OPEN ACCESS

Edited by:

Taku Kaitsuka

Kumamoto University, Japan

Reviewed by:

Ranen Aviner,

Stanford University, United States

Yingang Feng,

Qingdao Institute of Bioenergy and Bioprocess Technology (CAS),

China

*Correspondence:

Boris Negrutskil

negrutskii@imbg.org.ua

Specialty section:

This article was submitted to

Protein and RNA Networks,

a section of the journal

Frontiers in Molecular Biosciences

Received: 24 February 2020

Accepted: 20 March 2020

Published: 09 April 2020

Citation:

Negrutskii B (2020)

Non-translational Connections of eEF1B in the Cytoplasm

and Nucleus of Cancer Cells.

Front. Mol. Biosci. 7:56.

doi: $10.3389 /$ fmolb.2020.00056

\section{Non-translational Connections of eEF1B in the Cytoplasm and Nucleus of Cancer Cells}

\author{
Boris Negrutskii* \\ Department of Structural and Functional Proteomics, Institute of Molecular Biology and Genetics, National Academy \\ of Sciences, Kyiv, Ukraine
}

The human translation machinery includes three types of supramolecular complexes involved in elongation of the polypeptide chain: the ribosome, complex of elongation factors eEF1B and multienzyme aminoacyl-tRNA synthetase complex. Of the above, eEF1B is the least investigated assembly. Recently, a number of studies provided some insights into the structure of different eEF1B subunits and changes in their expression in cancer and other diseases. There is increasing agreement that possible disease-related functions of eEF1B are not necessarily related to its role in translation. This mini-review focuses on structural and functional features of the eEF1B complex while paying special attention to possible non-canonical functions of its subunits in cancer cells.

Keywords: supramolecular complex, translation, elongation factors, eEF1B, intracellular localization, cancer, cytoplasm, nucleus

\section{INTRODUCTION}

Several comprehensive reviews describing the basics of eEF1B structure and function have been published (see, for example, Le Sourd et al., 2006; Sasikumar et al., 2012). This mini-review summarizes novel structural, functional and expression data and presents recent information about possible cancer-related links of eEF1B subunits. Special attention is paid to newly emerging questions such as how stable the complex is in cancer tissues and how non-canonical involvements of its individual subunits are related to their intracellular localization. I regret that some important features of eEF1B remained undescribed due to space constrains.

\section{Structural Insights}

From the moment of its discovery, the eEF1B complex was considered as a stable unit which is essential for peptide elongation on the $80 \mathrm{~S}$ ribosome. The human complex comprises three subunits: eEF1B $\alpha$ (EEF1B2), eEF1B $\beta$ (EEF1D), and eEF1B $\gamma$ (EEF1G), according to established nomenclature (IUBMB, 1996).

$\mathrm{eEF} 1 \mathrm{~B} \alpha$ is a non-globular protein which shows a noticeably extended shape in solution (Trosiuk et al., 2016). The C-terminal part of eEF1B $\alpha$ executes nucleotide exchange while the $\mathrm{N}$-terminal fragment connects the protein with the eEF1B $\gamma$ subunit. The N-terminal part of eEF1B $\alpha$ plays an autoinhibitory role, while the presence of eEF1B $\gamma$ stimulates eEF1B $\alpha$-mediated nucleotide exchange (Trosiuk et al., 2016). The NMR-derived structure of the part of the eEF1B $\alpha$ C-terminal domain is known (Pérez et al., 1999).

$\mathrm{eEF} 1 \mathrm{~B} \beta$ and $\mathrm{eEF} 1 \mathrm{~B} \alpha$ have similar domain structure. The C-terminal part of eEF1B $\beta$ is highly homologous to the $\mathrm{C}$-terminal domain of $\mathrm{eEF} 1 \mathrm{~B} \alpha$, while the $\mathrm{N}$-terminal fragment has the unique 
amino acid sequence, a part of which is a leucine-zipper structure responsible for oligomerization of eEF1B $\beta$ (Bondarchuk et al., 2016). The very $\mathrm{N}$-terminal fragment (1-77 amino acid residues) binds eEF1B $\gamma$ and, possibly, other proteins (Bondarchuk et al., 2019), however, we cannot exclude at present that the remaining part of the eEF1B $\beta$ N-terminal domain is also involved in eEF1B $\gamma$ binding. This domain shows a dynamic spatial organization provided by $\alpha$-helical segments linked by flexible linkers (Bondarchuk et al., 2019). The NMR-derived structure of the eEF1B $\beta$ C-terminal fragment is known (Wu et al., 2016).

$\mathrm{eEF} 1 \mathrm{~B} \gamma$ has no nucleotide exchange activity while playing instead a scaffold role in the complex as it hosts eEF1B $\alpha$ and eEF1B $\beta$. Structural investigation of this subunit is complicated by its high tendency to aggregate (Sheu and Traugh, 1997, Kamiie et al., 2003). The NMR-derived structure of the $19 \mathrm{kDa}$ C-terminal fragment of human protein (Vanwetswinkel et al., 2003) and crystal structure of the N-terminal domain of yeast protein (Jeppesen et al., 2003) are known.

Of note, unpublished structures of the complex of the eEF1B $\alpha$ $\mathrm{N}$-terminal domain and eEF1B $\gamma \mathrm{N}$-terminal domain and of the complex of the eEF1B $\gamma$ N-terminal domain and eEF1B $\beta$ $\mathrm{N}$-terminal domain are available in PDB (5DQS and 5JPO, correspondingly).

\section{Functional Insights \\ Translation Functions}

To date, the only established function of the eEF1B complex is to catalyze nucleotide exchange in another elongation factor, eEF1A, which supplies the ribosomes with aminoacyl-tRNAs. Both $\mathrm{eEF} 1 \mathrm{~B} \alpha$ and $\mathrm{eEF} 1 \mathrm{~B} \beta$ possess the nucleotide exchange activity. Importantly, different tissue-specific isoforms of eEF1A showed different eEF1B $\alpha$-dependence in vitro, namely, eEF1A2 rather than eEF1A1 strongly needed eEF1B $\alpha$ for nucleotide exchange (Trosiuk et al., 2016). No corresponding information about $\mathrm{eEF} 1 \mathrm{~B} \beta$ is available. Deletion of the yeast eEF1B $\gamma$ gene induced increased misreading of near-cognate codons and decreased misreading of non-cognate codons (Plant et al., 2007). Interestingly, the yeast eEF1B complex was suggested to serve as an exchange agent for translation termination factor eRF3 (Valouev et al., 2009).

\section{Non-canonical Functions}

Beyond translation, subunits of eEF1B may be involved in many different processes, including cell cycle control, cytoskeleton regulation, and stress response, as summarized in Sasikumar et al. (2012). This section is focused on new non-canonical links of eEF1B revealed by a proteomic approach. Posttranslational modification-related regulation of eEF1B subunits is not described here in full due to space constrains.

\section{$e E F 1 B \alpha$}

There is not too much data on non-canonical functions of eEF1B $\alpha$. This protein interacts with nuclear/cytoplasmic prolylisomerase FKBP25 (FKBP3) (Galat et al., 2014), which is a nucleic acid binding protein involved in both repair of DNA double-strand breaks (Dilworth et al., 2019) and microtubule polymerization (Dilworth et al., 2018). Depletion of nucleoside diphosphate kinase A (NME1) lead to a redistribution of eEF1B $\alpha$ from the cytoplasm to the endoplasmic reticulum fraction in mouse liver (Bruneel et al., 2011). Importantly, nucleoside diphosphate kinase A can be transferred to the nucleus where it promotes the non-homologous end joining of the DNA doublestrand breaks (Xue et al., 2019) and takes part in transcription (Puts et al., 2018).

The N-terminal fragment of eEF1B $\alpha$ was reportedly secreted from mouse astrocytes upon stimulation of a $\mathrm{Ca}^{2+}$ increase by bradykinin treatment (Yin et al., 2012) though there was no explanation for the phenomenon.

\section{eEF1B $\beta$}

Some non-canonical involvements of eEF1B $\beta$ in cell functioning are predicted. eEF1B $\beta$ is a potential substrate of sucrose nonfermenting related kinase (SNRK) which controls adipose inflammation and energy homeostasis (Li et al., 2018). Importantly, knocking down eEF1B $\beta$ expression in adipocytes induced inflammation ( $\mathrm{Li}$ et al., 2018). Decreased expression of eEF1B $\beta$ was detected during inflammation in lipid A-treated mouse epithelial cells (Takano et al., 2016).

eEF1B $\beta$ inhibited auto-ubiquitination and degradation of E3 ubiquitin ligase (SIAH-1) (Wu et al., 2011). There was 3-fold increase in the amount of eEF1B $\beta$ in pancreas of diabetic rats (Jiang et al., 2011). Upregulation of eEF1B $\beta$ was reported in lungs of chronic hypoxic rats with pulmonary hypertension. Peculiarly, eEF1B $\beta$ was heavily stained in the apical region of the epithelium in bronchioles, as well as in lymphocytes and macrophages interstitially dispersed in the epithelium (Østergaard et al., 2011).

eEF1B $\beta$ was markedly decreased in senescent human fetal lung diploid fibroblasts cells, while treatment of these cells with a putative anti-aging agent caused an opposite effect (Xing et al., 2018). Similar influence of senescence on eEF1B $\alpha$ (Byun et al., 2009) and eEF1B $\beta$ (Takano et al., 2016), as well as on eEF1A1 (Byun et al., 2009) apparently reflects the global inhibition of protein synthesis during aging which supposedly occurs due to suppression of the whole eEF1B complex. Thus, an effect of senescence on eEF1B canonical function is also possible.

\section{eEF1B $\gamma$}

The eEF1B $\gamma$ subunit shows a large variety of prospective noncanonical functions. A high in unsaturated fatty acids diet during gestation and lactation caused more than 5-fold eEF1B $\gamma$ increase in neonatal offspring liver in rats (Novak et al., 2009). eEF1B $\gamma$ was decreased in human myometrium after exogenous oxytocin administration while a reciprocal effect was observed upon administration of an oxytocin antagonist (de Wit et al., 2010).

Yeast eEF1B $\gamma$ and not the eEF1B $\gamma-\mathrm{eEF} 1 \mathrm{~B} \alpha$ complex were supposedly involved to the retrograde Golgi to ER transport (Esposito and Kinzy, 2010). In other fungi, Aspergillus fumigatus, deletion of eEF1B $\gamma$ was associated with changes in oxidative stress and actin cytoskeleton organization (O'Keeffe et al., 2013). The gills from Atlantic halibut exposed to water containing high $\mathrm{CO}_{2}$ concentration showed upregulation of eEF1B $\gamma$ (Bresolin de Souza et al., 2014).

eEF1B $\gamma$ was one of the candidates to participate in loading of microRNAs into extracellular vesicles that may be needed 
to preserve microRNAs and transfer them to extracellular fluid (Hagiwara et al., 2015). eEF1B $\gamma$ interacted with components of DNA damage response machinery (Pisani et al., 2016). Yeast eEF1B $\gamma$ was found in stress granules upon heat shock (Grousl et al., 2013; Cherkasov et al., 2015). Interestingly, upon heat stress of yeast, all subunits of the eEF1B complex aggregate quickly and synchronously, contrary to eEF1A (Wallace et al., 2015). eEF1B $\gamma$ was identified as a member of the pre-mRNA $3^{\prime}$ end cleavage complex (Shi et al., 2009).

Oncogene-induced senescence in primary human fibroblasts caused a marked (more than 9-fold) increase in ubiquitination of eEF1B $\gamma$. Peculiarly, no changes in ubiquitination of other subunits of eEF1B were found, while eEF1A, several aminoacyltRNA synthetases and translation initiation factors were also hyper ubiqiutinated (Bengsch et al., 2015). It should be noted, however, that mono- and polyubiquitination of eEF1B $\gamma$ were not differentiated in this case. eEF1B $\gamma$ was reported to positively affect K63-linked polyubiquitination of mitochondrial antiviralsignaling protein (MAVS) and negatively influence its K48-linked polyubiquitination resulting in the increased abundance of this antiviral protein (Liu et al., 2014).

An EEF1G- anaplastic lymphoma kinase (ALK) gene fusion was recently found in two pediatric patients with anaplastic large cell lymphoma (Palacios et al., 2017). In the context of the review, it is important that a fusion of the eEF1B $\gamma$ $\mathrm{N}$-terminal domain provided exclusively cytoplasmic localization of the fusion protein (Ceccon et al., 2016) suggesting that the $\mathrm{N}$-terminal domain of eEF1B $\gamma$ could not possibly be related to nuclear localization of eEF1B $\gamma$ alone.

Drosophila eEF1B $\gamma$ is a substrate of LAMMER kinase (DOA) and can be phosphorylated by human kinase LAMMER/CLK2 (CLK2) as well (Fan et al., 2010). Importantly, DOA kinase and $\mathrm{eEF} 1 \mathrm{~B} \gamma$ negatively regulated motor-mediated transport of membrane organelles along microtubules depending on the phosphorylation of Ser 294 in eEF1B $\gamma$ (Serpinskaya et al., 2014).

\section{eEF1B Proteins in Cancer}

The levels of mRNA and a protein coded by this mRNA do not often correlate (Liu et al., 2016) which is valid for eEF1B subunits as well (Veremieva et al., 2011, 2014; Flores et al., 2016). This mini-review is focused on eEF1B proteins, therefore cancer-related changes in the levels of corresponding mRNAs are not considered here, although such changes may be of marker/prognostic importance (Hassan et al., 2018; Biterge-Sut, 2019). It is noteworthy that the data described in this section may be related to both canonical and non-canonical functioning of eEF1B subunits.

Not too much information is available on eEF1B $\alpha$ association with cancer. Increased expression of $\operatorname{eEF} 1 \mathrm{~B} \alpha$ was reported as a negative prognosis marker in stomach cancer (Jia et al., 2018). Besides, ionizing radiation-induced senescence of breast cancer, lung cancer and colon cancer cell lines was accompanied by a significant decrease in eEF1B $\alpha$ (Byun et al., 2009).

eEF1B $\beta$ was long known as a cadmium-induced protooncogene (Joseph et al., 2002; Lei et al., 2002; Lei et al., 2010). Recently, eEF1B $\beta$ was proposed as a blood marker for cadmium exposure ( $\mathrm{Lu}$ et al., 2013). This protein was upregulated in the metastatic canine mammary carcinoma (Klopfleisch et al., 2010) and human oral squamous cell carcinoma (Flores et al., 2016) tissues, as well as in 5-fluorouracil-resistant human breast cancer cells (Zheng et al., 2010). Interestingly, knocking down of eEF1B $\beta$ mRNA was accompanied by the opposite effects on the proliferation and epithelial mesenchymal transition (EMT)/invasion capabilities of squamous cell carcinoma cells (Flores et al., 2016). eEF1B $\beta$ was upregulated in osteosarcoma and suggested to play a tumor-promoting role by facilitating the Akt-mTOR and Akt-Bad signaling pathways (Cheng et al., 2018).

The level of eEF1B $\gamma$ was increased in oral squamous cell carcinoma (Flores et al., 2016) and hepatic metastatic colorectal cancer (Yang et al., 2019). eEF1B $\gamma$ was downregulated in HepG2 cells treated with Nomura's jellyfish venom used as an anticancer drug (Choudhary et al., 2018). Also, the protein was essentially decreased in cervical cancer specimens taken from patients after treatment with paclitaxel and cisplatin (Liu et al., 2011). eEF1B $\gamma$ may be an urine marker of bladder cancer (Chen et al., 2009). Interestingly, eEF1B $\gamma$ was 3-fold decreased in benign pleomorphic adenoma of the human parotid gland (Mutlu et al., 2017).

\section{Complex Matter}

One may notice that cancer-related changes of individual eEF1B subunits were observed far more often than corresponding changes of all subunits together. It raised a question whether malignant tumors induce deregulation of individual subunits rather than the whole eEF1B complex?

An attempt to meet this challenge was undertaken in series of papers where cancer-related changes in the level of all three eEF1B subunits were analyzed simultaneously in the same tissue samples (Veremieva et al., 2011, 2014). More than two-fold upregulation of at least one eEF1B subunit was observed in $72 \%$ of 25 cardioesophageal cancer samples. The simultaneous increase in the level of all three eEF1B subunits was observed in the one, simultaneous upregulation of eEF1B $\alpha$ and $e E F 1 B \beta$ was observed in two cases and simultaneous upregulation of eEF1B $\beta$ and $e E F 1 B \gamma$ was found in four cases while no correlated increase of eEF1B $\alpha$ and $\mathrm{eEF} 1 \mathrm{~B} \gamma$ was detected (Veremieva et al., 2011). More than two-fold rise in the level of at least one eEF1B subunit was observed in $52 \%$ of 25 lung carcinoma samples. Again, the simultaneous increase in the level of all three eEF1B subunits was observed in one case, simultaneous upregulation of $\mathrm{eEF} 1 \mathrm{~B} \alpha$ and $\mathrm{eEF} 1 \mathrm{~B} \beta$ was also found in one case, simultaneous upregulation of eEF1B $\beta$ and $e E F 1 B \gamma$ was observed in five cases while no correlated elevation of eEF1B $\alpha$ and $\mathrm{eEF} 1 \mathrm{~B} \gamma$ was found (Veremieva et al., 2014). The authors concluded that cancer-related upregulation of individual subunits rather than the whole eEF1B complex takes place in both cancers. Interestingly, the observed trend of coordinated up-regulation of eEF1B $\beta$ and $e E F 1 B \gamma$ was spotted also in oral squamous cell carcinoma (Flores et al., 2016). It is interesting that eEF1B $\beta$ and $\mathrm{eEF} 1 \mathrm{~B} \gamma$ showed also a parallel increase in the prenatal as compared to postnatal expression levels in mice brain and liver (Cao et al., 2014). Further experiments should reveal if these correlative changes reflect the formation in vivo of a stable complex eEF1B $\beta-e E F 1 B \gamma$. 


\section{Are Non-Canonical Functions of eEF1B Subunits Associated With Their Intracellular Localization?}

Non-canonical functioning of eEF1B and/or its subunits is not yet attributed to specific cellular compartments. As translation occurs in the cytoplasm then the cytoplasmic localization of eEF1B is obvious. However, signs of the nuclear localization of eEF1B subunits were displayed in the normal (Drosophila embryos, human cardioesophageal junction, human lung) and cancer (cardioesophageal carcinoma, lung cancer, oral squamous cell carcinoma) tissues as well as in lung adenocarcinoma cells A549 (Fan et al., 2010; Veremieva et al., 2011; Veremieva et al., 2014; Flores et al., 2016). In an attempt to attribute possible noncanonical eEF1B functions to the specific cellular compartments the partners of eEF1B $\beta$ and eEF1B $\gamma$ in the cytoplasm and nucleus of human lung carcinoma cells were identified experimentally and analyzed by several bioinformatics approaches (Kapustian et al., 2016, 2017, 2018, 2019). Cytoplasmic eEF1B $\beta$ was predicted to be involved into four protein networks representing cell cycle regulation, DNA replication and repair, chromatin remodeling and chaperoning machinery (Kapustian et al., 2016). Nuclear eEF1B $\beta$ interacted with proteins involved into RNA transcription and splicing, microRNA turnover, degradation of mRNA and proteins, DNA damage response. It could be also involved into adipose tissue biology and EMT (Kapustian et al., 2017). Cytoplasmic eEF1B $\gamma$ could participate in mRNA splicing and processing, nucleosome remodeling, cell cycle regulation, viral RNA transcription, oxidative stress response (Kapustian et al., 2018). Nuclear eEF1B $\gamma$ supposedly took part in splicing of pre-mRNA and regulation of mRNA stability, cytoskeleton-membrane linking and cellular trafficking (Kapustian et al., 2019).

One should mention that the co-immunoprecipitation data are not sufficient to provide an explicit evidence for an involvement of eEF1B subunits to one or the other process. However, analysis of these data is significant in that it provides a ground to develop the future direction of eEF1B research.

The Table 1 summarizes potential involvements of differently located eEF1B subunits in different cellular processes. No exclusive function can be attributed to cytoplasmic eEF1B $\beta$, while

TABLE 1 | Possible non-translational involvements of eEF1B subunits.

\begin{tabular}{|c|c|c|c|c|c|}
\hline & cyto eEF1B $\beta$ & nuclear eEF1B $\beta$ & cyto eEF1B $\gamma$ & nuclear eEF1B $\gamma$ & eEF1B $\alpha^{\#}$ \\
\hline Chaperoning & Kapustian et al., $2016^{+}$ & & & & \\
\hline MicroRNA turnover & & Kapustian et al., $2017^{+}$ & Hagiwara et al., 2015+*. & & \\
\hline Adipose tissue biology & & $\begin{array}{l}\text { Kapustian et al., } 2017^{+} \text {; } \\
\text { Li et al., } 2018^{+*}\end{array}$ & & & \\
\hline EMT & Kapustian et al., 2016+ & $\begin{array}{l}\text { Flores et al., 2016+*; } \\
\text { Kapustian et al., } 2017^{+}\end{array}$ & & & \\
\hline Oxidative stress response & & & $\begin{array}{l}\text { O'Keeffe et al., 2013+*; } \\
\text { Kapustian et al., 2018+ }\end{array}$ & & \\
\hline $\begin{array}{l}\text { Cytoskeleton-membrane } \\
\text { link }\end{array}$ & Ong et al., $2003^{+\star}$ & & & Kapustian et al., 2019+ & \\
\hline Cellular trafficking & Kapustian et al., 2016+ & & & $\begin{array}{l}\text { Serpinskaya et al., 2014+*; } \\
\text { Kapustian et al., 2019+ }\end{array}$ & \\
\hline Splicing of mRNA & & Kapustian et al., 2017+ & Kapustian et al., 2018+ & $\begin{array}{l}\text { Fan et al., 2010; Kapustian } \\
\text { et al., 2019+ }\end{array}$ & \\
\hline DNA repair & Kapustian et al., 2016+ & Kapustian et al., $2017^{+}$ & & & $\begin{array}{l}\text { Bruneel et al., 2011; } \\
\text { Galat et al., } 2014\end{array}$ \\
\hline $\begin{array}{l}\text { Chromatin and nucleosome } \\
\text { remodeling }\end{array}$ & Kapustian et al., 2016+ & & Kapustian et al., 2018+ & & \\
\hline Cell cycle regulation & $\begin{array}{l}\text { Flores et al., 2016 } \\
\text { Kapustian et al., } 2016^{+}\end{array}$ & & Kapustian et al., 2018+ & & \\
\hline Transcription & & Kapustian et al., $2017^{+}$ & Kapustian et al., 2018+ & & \\
\hline $\begin{array}{l}\text { Stability and degradation of } \\
\text { mRNA }\end{array}$ & & Kapustian et al., 2017+ & & Kapustian et al., 2019+ & \\
\hline Microtubule interaction & Ong et al., $2003^{+*}$ & & $\begin{array}{l}\text { Janssen and Möller, } \\
1988^{+\star}\end{array}$ & & Galat et al., 2014 \\
\hline $\begin{array}{l}\text { Actin cytoskeleton } \\
\text { interaction }\end{array}$ & & & Furukawa et al., $2001^{+\star}$ & & $\begin{array}{l}\text { Furukawa et al., } \\
2001\end{array}$ \\
\hline $\begin{array}{l}\text { Intermediate filaments } \\
\text { interaction }\end{array}$ & & & Kim et al., $2007^{+}$ & & \\
\hline Ubiquitination & Wu et al., $2011^{+*}$ & & $\begin{array}{l}\text { Liu et al., 2014; Bengsch } \\
\text { et al., 2015+* }\end{array}$ & & \\
\hline Senescence & $\begin{array}{l}\text { Takano et al., 2016; Xing } \\
\text { et al., } 2018^{+*}\end{array}$ & & & & Byun et al., 2009 \\
\hline
\end{tabular}

${ }^{+}$Cytoplasmic or nuclear localization is defined. ${ }^{+*}$ Cytoplasmic or nuclear localization is not defined. ${ }^{\#}$ Intracellular localization is not studied. 
the only nucleus-localized eEF1B $\beta$ may take part in adipose tissue biology (Kapustian et al., 2017). Both cytoplasmic and nuclear eEF1B $\beta$ may be involved in EMT (Kapustian et al., 2016, 2017). The only cytoplasmic eEF1B $\gamma$ may participate in oxidative stress response (Kapustian et al., 2018). Taking into account the above-mentioned trends toward the coordinated upregulation of $\mathrm{eEF} 1 \mathrm{~B} \beta$ and $\mathrm{eEF} 1 \mathrm{~B} \gamma$ in human cancer tissues it would be interesting to decipher the processes in which these subunits may be involved in concert. For the cytoplasmic fraction, those are, surprisingly, chromatin/nucleosome remodeling and cell cycle regulation (Kapustian et al., 2016, 2018) while for the nuclear fraction it is regulation of the mRNA stability and degradation (Kapustian et al., 2017, 2019). One should mention, however, that mixed intracellular localization is characteristic for components of these processes in cell. Besides, a number of processes may involve both cyto- and nucleo-localized eEF1B $\beta$ and eEF1B $\gamma$; these are microRNA turnover, cytoskeleton-membrane linking, cellular trafficking, mRNA transcription and splicing (Kapustian et al., 2016, 2017, 2018, 2019). This apparently reflects cytonucleo shuttling of subunits involved into these processes.

DNA repair may implicate both eEF1B $\beta$ and eEF1B $\alpha$ (Bruneel et al., 2011; Galat et al., 2014; Kapustian et al., 2016; Kapustian et al., 2017). This suggests an involvement of the whole eEF1B complex, as these subunits interact with each other via eEF1B $\gamma$.

The viral infection-related functions of the eEF1B complex well described in Li et al. (2013) are not a subject of this minireview, though some virus-related partners of eEF1B subunits were found in the cytoplasmic and nuclear fractions of lung carcinoma cells (Kapustian et al., 2017; Kapustian et al., 2018; Kapustian et al., 2019).

Surprisingly, a number of potential protein partners of cytoplasmic eEF1B $\gamma$ were linked to corneal diseases, particularly retinoblastoma (Kapustian et al., 2018; Kapustian et al., 2019). On the contrary, several possible partners of nuclear $\mathrm{eEF} 1 \mathrm{~B} \gamma$ were involved to different neurodegenerative disorders

\section{REFERENCES}

Bengsch, F., Tu, Z., Tang, H. Y., Zhu, H., Speicher, D. W., and Zhang, R. (2015). Comprehensive analysis of the ubiquitinome during oncogene-induced senescence in human fibroblasts. Cell Cycle 14, 1540-1547. doi: 10.1080/ 15384101.2015.1026492

Biterge-Sut, B. (2019). Alterations in Eukaryotic Elongation Factor complex proteins (EEF1s) in cancer and their implications in epigenetic regulation. Life Sci. 238:116977. doi: 10.1016/j.lfs.2019.116977

Bondarchuk, T. V., Lozhko, D. M., Shalak, V. F., Fatalska, A., Szczepanowski, R. H., Dadlez, M., et al. (2019). The protein-binding N-terminal domain of human translation elongation factor $1 \mathrm{~B} \beta$ possesses a dynamic $\alpha$-helical structural organization. Int. J. Biol. Macromol. 126, 899-907. doi: 10.1016/j.ijbiomac.2018. 12.220

Bondarchuk, T. V., Shalak, V. F., Negrutskii, B. S., and El'skaya, A. V. (2016). Leucine-zipper motif is responsible for self-association of translation elongation factor 1B $\beta$. Biopolym. Cell 32, 9-20. doi: 10.7124/bc.000907

Bresolin de Souza, K., Jutfelt, F., Kling, P., Förlin, L., and Sturve, J. (2014). Effects of increased $\mathrm{CO}_{2}$ on fish gill and plasma proteome. PLoS One 9:e102901. doi: 10.1371/journal.pone.0102901

Bruneel, A., Wendum, D., Labas, V., Mulner-Lorillon, O., Vinh, J., Bosselut, N., et al. (2011). Proteomic analysis of NME1/NDPK A null mouse liver: evidence for a post-translational regulation of annexin IV and EF-1B $\alpha$. Naunyn
(Kapustian et al., 2018; Kapustian et al., 2019). One cannot exclude that the specific localization of subunits may be associated with these diseases. The potential involvement of eEF1B in neurodevelopmental disorders was recently reviewed (McLachlan et al., 2019).

\section{CONCLUSION}

There are two recently emerging directions of eEF1B complex studies. These are: (i) exploring the molecular mechanisms and regulatory consequences of the appearance of its individual subunits under abnormal cellular conditions; (ii) studying the links of different intracellular localization of the eEF1B complex and/or its individual subunits to various nontranslational processes and, possibly, diseases. Combination of these approaches should be of interest for upcoming investigators to couple fundamental eEF1B knowledge with its evolving clinical significance.

\section{AUTHOR CONTRIBUTIONS}

The author confirms being the sole contributor of this work and has approved it for publication.

\section{FUNDING}

A contribution of the Interdisciplinary program of scientific research "Molecular and cell biotechnologies for medicine, industry and agriculture" of National Academy of Sciences of Ukraine and the Ukraine State program "Supporting development of the priority directions of scientific research" (6541230) to the author's lab research is greatly appreciated.

Schmiedebergs Arch. Pharmacol. 384, 407-419. doi: 10.1007/s00210-0110639-5

Byun, H. O., Han, N. K., Lee, H. J., Kim, K. B., Ko, Y. G., Yoon, G., et al. (2009). Cathepsin D and eukaryotic translation elongation factor 1 as promising markers of cellular senescence. Cancer Res. 69, 4638-4647. doi: 10.1158/00085472.CAN-08-4042

Cao, Y., Portela, M., Janikiewicz, J., Doig, J., and Abbott, C. M. (2014). Characterisation of translation elongation factor eEF1B subunit expression in mammalian cells and tissues and co-localisation with eEF1A2. PLoS One 9:e114117. doi: 10.1371/journal.pone.0114117

Ceccon, M., Merlo, M. E. B., Mologni, L., Poggio, T., Varesio, L. M., Menotti, M., et al. (2016). Excess of NPM-ALK oncogenic signaling promotes cellular apoptosis and drug dependency. Oncogene 35, 3854-3865. doi: 10.1038/onc. 2015.456

Chen, L., Chen, W., Zhao, L., Yu, H. Z., and Li, X. (2009). Immunoscreening of urinary bladder cancer cDNA library and identification of potential tumor antigen. World J. Urol. 27, 107-112. doi: 10.1007/s00345-008-0326-4

Cheng, D. D., Li, S. J., Zhu, B., Zhou, S. M., and Yang, Q. C. (2018). EEF1D overexpression promotes osteosarcoma cell proliferation by facilitating AktmTOR and Akt-bad signaling. J. Exp. Clin. Cancer Res. 37, 50. doi: 10.1186/ s13046-018-0715-5

Cherkasov, V., Grousl, T., Theer, P., Vainshtein, Y., Glässer, C., Mongis, C., et al. (2015). Systemic control of protein synthesis through sequestration of 
translation and ribosome biogenesis factors during severe heat stress. FEBS Lett. 589, 3654-3664. doi: 10.1016/j.febslet.2015.10.010

Choudhary, I., Lee, H., Pyo, M. J., Heo, Y., Chae, J., Yum, S. S., et al. (2018). Proteomic Investigation to Identify Anticancer Targets of Nemopilema nomurai Jellyfish Venom in Human Hepatocarcinoma HepG2 Cells. Toxins 10:E194. doi: 10.3390/toxins10050194

de Wit, N. C., Heck, A. J., and Thornton, S. (2010). The effect of oxytocin and an oxytocin antagonist on the human myometrial proteome. Reprod. Sci. 17, 40-46. doi: 10.1177/1933719109345287

Dilworth, D., Gong, F., Miller, K., and Nelson, C. J. (2019). FKBP25 participates in DNA double-strand break repair. Biochem. Cell Biol. 98, 42-49. doi: 10.1139/ bcb-2018-0328

Dilworth, D., Gudavicius, G., Xu, X., Boyce, A. K. J., O’Sullivan, C., Serpa, J. J., et al. (2018). The prolyl isomerase FKBP25 regulates microtubule polymerization impacting cell cycle progression and genomic stability. Nucleic Acids Res. 46, 2459-2478. doi: 10.1093/nar/gky008

Esposito, A. M., and Kinzy, T. G. (2010). The eukaryotic translation elongation Factor 1Bgamma has a non-guanine nucleotide exchange factor role in protein metabolism. J. Biol. Chem. 285, 37995-38004. doi: 10.1074/jbc.M110.160887

Fan, Y., Schlierf, M., Gaspar, A. C., Dreux, C., Kpebe, A., Chaney, L., et al. (2010). Drosophila translational elongation factor-1gamma is modified in response to DOA kinase activity and is essential for cellular viability. Genetics 184, 141-154. doi: 10.1534/genetics.109.109553

Flores, I. L., Kawahara, R., Miguel, M. C., Granato, D. C., Domingues, R. R., Macedo, C. C., et al. (2016). EEF1D modulates proliferation and epithelialmesenchymal transition in oral squamous cell carcinoma. Clin. Sci. 130, 785-799. doi: $10.1042 / C S 20150646$

Furukawa, R., Jinks, T. M., Tishgarten, T., Mazzawi, M., Morris, D. R., and Fechheimer, M. (2001). Elongation factor 1beta is an actin-binding protein. Biochim. Biophys. Acta 1527, 130-140.

Galat, A., Thai, R., and Stura, E. A. (2014). Diversified targets of FKBP25 and its complex with rapamycin. Int. J. Biol. Macromol. 69, 344-352. doi: 10.1016/j. ijbiomac.2014.05.060

Grousl, T., Ivanov, P., Malcova, I., Pompach, P., Frydlova, I., Slaba, R., et al. (2013). Heat shock-induced accumulation of translation elongation and termination factors precedes assembly of stress granules in S. cerevisiae. PLoS One 8:e57083. doi: 10.1371/journal.pone. 0057083

Hagiwara, K., Katsuda, T., Gailhouste, L., Kosaka, N., and Ochiya, T. (2015). Commitment of Annexin A2 in recruitment of microRNAs into extracellular vesicles. FEBS Lett. 589, 4071-4078. doi: 10.1016/j.febslet.2015.11.036

Hassan, M. K., Kumar, D., Naik, M., and Dixit, M. (2018). The expression profile and prognostic significance of eukaryotic translation elongation factors in different cancers. PLoS One 13:e0191377. doi: 10.1371/journal.pone.0191377

IUBMB (1996). Prokaryotic and eukaryotic translation factors. Ad Hoc Nomenclature Subcommittee Report. Biochimie 78, 1119-1122.

Janssen, G., and Möller, W. (1988). Elongation factor 1 beta gamma from Artemia. Purification and properties of its subunits. Eur. J. Biochem. 171, 119-129.

Jeppesen, M. G., Ortiz, P., Shepard, W., Kinzy, T. G., Nyborg, J., and Andersen, G. R. (2003). The crystal structure of the glutathione S-transferase-like domain of elongation factor 1Bgamma from Saccharomyces cerevisiae. J. Biol. Chem. 278, 47190-47198.

Jia, L., Yang, T., Gu, X., Zhao, W., Tang, Q., Wang, X., et al. (2018). Translation elongation factor eEF1B $\alpha$ is identified as a novel prognostic marker of gastric cancer. Int. J. Biol. Macromol. 126, 345-351. doi: 10.1016/j.ijbiomac.2018.12.126

Jiang, Y. L., Ning, Y., Ma, X. L., Liu, Y. Y., Wang, Y., Zhang, Z., et al. (2011). Alteration of the proteome profile of the pancreas in diabetic rats induced by streptozotocin. Int. J. Mol. Med. 28, 153-160. doi: 10.3892/ijmm.20 11.696

Joseph, P., Lei, Y. X., Whong, W. Z., and Ong, T. M. (2002). Oncogenic potential of mouse translation elongation factor-1 delta, a novel cadmium-responsive proto-oncogene. J. Biol. Chem. 277, 6131-6136. doi: 10.1074/jbc.m109373200

Kamiie, K., Yamashita, T., Taira, H., Kidou, S., and Ejiri, S. (2003). Interaction between elongation factors 1beta and lgamma from Bombyx mori silk gland. Biosci. Biotechnol. Biochem. 67, 1522-1529.

Kapustian, L. M., Dadlez, M., and Negrutskii, B. S. (2016). Non-canonical interactions of the $\beta$ subunit of the translation elongation complex eEF1B and analysis of their possible functional role. Biopolym. Cell 32, 347-358. doi: $10.7124 /$ bc.00092f
Kapustian, L. M., Dadlez, M., and Negrutskii, B. S. (2017). Protein partners of the eEF1B $\beta$ subunit of the translation elongation complex eEF1B in the nuclear fraction of human lung carcinoma cells. Biopolym. Cell 33, 243-255. doi: $10.7124 /$ bc.00095d

Kapustian, L. M., Lysetsky, I. L., Bondarchuk, T. V., Novosylna, O. V., and Negrutskii, B. S. (2018). Mass-spectrometric and bioinformatic analysis of eEF1B $\gamma$ interactome in the cytoplasmic fraction of A549 cells. Biopolym. Cell 34, 292-302. doi: 10.7124/bc.000982

Kapustian, L. M., Lysetsky, I. L., Bondarchuk, T. V., Novosylna, O. V., and Negrutskii, B. S. (2019). Analysis of eEF1B $\gamma$ interactome in the nuclear fraction of A549 human lung adenocarcinoma cells. Biopolym. Cell 35, 268-287. doi: 10.7124/bc.000a0a

Kim, S., Kellner, J., Lee, C. H., and Coulombe, P. A. (2007). Interaction between the keratin cytoskeleton and eEF1Bgamma affects protein synthesis in epithelial cells. Nat. Struct. Mol. Biol. 14, 982-983. doi: 10.1038/nsmb1301

Klopfleisch, R., Klose, P., Weise, C., Bondzio, A., Multhaup, G., Einspanier, R., et al. (2010). Proteome of metastatic canine mammary carcinomas: similarities to and differences from human breast cancer. J. Proteome Res. 9, 6380-6391. doi: $10.1021 /$ pr100671c

Le Sourd, F., Boulben, S., Le Bouffant, R., Cormier, P., Morales, J., Belle, R., et al. (2006). eEF1B: At the dawn of the 21st century. Biochim. Biophys. Acta 1759, 13-31. doi: 10.1016/j.bbaexp.2006.02.003

Lei, Y. X., Chen, J. K., and Wu, Z. L. (2002). Blocking the translation elongation factor-1 delta with its antisense mRNA results in a significant reversal of its oncogenic potential. Teratog. Carcinog. Mutagen. 22, 377-383. doi: 10.1002/ tcm. 10034

Lei, Y. X., Wang, M., Wei, L., Lu, X., and Lin, H. Z. (2010). Alternative expression and sequence of human elongation factor-1 delta during malignant transformation of human bronchial epithelial cells induced by cadmium chloride. Biomed. Environ. Sci. 23, 151-157. doi: 10.1016/s0895-3988(10) 60045-1

Li, D., Wei, T., Abbott, C. M., and Harrich, D. (2013). The unexpected roles of eukaryotic translation elongation factors in RNA virus replication and pathogenesis. Microbiol. Mol. Biol. Rev. 77, 253-266. doi: 10.1128/MMBR. 00059-12

Li, J., Feng, B., Nie, Y., Jiao, P., Lin, X., Huang, M., et al. (2018). Sucrose nonfermenting-related kinase regulates both adipose inflammation and energy homeostasis in mice and humans. Diabetes Metab. Res. Rev. 67, 400-411. doi: $10.2337 / \mathrm{db} 17-0745$

Liu, D., Sheng, C., Gao, S., Jiang, W., Li, J., Yao, C., et al. (2014). eEF1B $\gamma$ is a positive regulator of NF-êB signaling pathway. Biochem. Biophys. Res. Commun. 446, 523-528. doi: 10.1016/j.bbrc.2014.02.137

Liu, H., Han, Y., Mi, R., Zhang, Y., Su, G., Wang, H., et al. (2011). Identification of cervical cancer proteins associated with treatment with paclitaxel and cisplatin in patients. Int. J. Gynecol. Cancer 21, 1452-1457. doi: 10.1097/IGC. 0b013e31822491d0

Liu, Y., Beyer, A., and Aebersold, R. (2016). On the dependency of cellular protein levels on mRNA abundance. Cell 165, 535-550. doi: 10.1016/j.cell.2016.03.014

Lu, Q., Lei, Y. X., He, C. C., and Lei, Z. N. (2013). Blood translation elongation factor- $1 \delta$ is a novel marker for cadmium exposure. Int. J. Mol. Sci. 14, 51825197. doi: $10.3390 /$ ijms 14035182

McLachlan, F., Sires, A. M., and Abbott, C. M. (2019). The role of translation elongation factor eEF1 subunits in neurodevelopmental disorders. Hum. Mutat. 40, 131-141. doi: 10.1002/humu.23677

Mutlu, A., Ozturk, M., Akpinar, G., Kasap, M., and Kanli, A. (2017). Proteomics analysis of pleomorphic adenoma of the human parotid gland. Eur. Arch. Otorhinolaryngol. 274, 3183-3195. doi: 10.1007/s00405-017-4608-6

Novak, E. M., Lee, E. K., Innis, S. M., and Keller, B. O. (2009). Identification of novel protein targets regulated by maternal dietary fatty acid composition in neonatal rat liver. J. Proteomics 73, 41-49. doi: 10.1016/j.jprot.2009.07.008

O'Keeffe, G., Jöchl, C., Kavanagh, K., and Doyle, S. (2013). Extensive proteomic remodeling is induced by eukaryotic translation elongation factor $1 \mathrm{~B} \gamma$ deletion in Aspergillus fumigatus. Protein Sci. 22, 1612-1622. doi: 10.1002/pro.2367

Ong, L. L., Connie, P. N., Ho, A., Aung, M. T., and Yu, H. (2003). Kinectin anchors the translation elongation factor- $1 \delta$ to the endoplasmic reticulum. J. Biol. Chem. 278, 32115-32123. doi: 10.1074/jbc.m210917200

Østergaard, L., Honoré, B., Thorsen, L. B., Baandrup, J., Eskildsen-Helmond, Y., Laursen, B. E., et al. (2011). Pulmonary pressure reduction attenuates 
expression of proteins identified by lung proteomic profiling in pulmonary hypertensive rats. Proteomics 11, 4492-4502. doi: 10.1002/pmic.201100171

Palacios, G., Shaw, T. I., Li, Y., Singh, R. K., Valentine, M., Sandlund, J. T., et al. (2017). Novel ALK fusion in anaplastic large cell lymphoma involving EEF1G, a subunit of the eukaryotic elongation factor-1 complex. Leukemia 31, 743-747. doi: 10.1038/leu.2016.331

Pérez, J. M., Siegal, G., Kriek, J., Hård, K., Dijk, J., Canters, G. W., et al. (1999). The solution structure of the guanine nucleotide exchange domain of human elongation factor lbeta reveals a striking resemblance to that of EF-Ts from Escherichia coli. Structure 7, 217-226. doi: 10.1016/s0969-2126(99)80027-6

Pisani, C., Onori, A., Gabanella, F., Delle Monache, F., Borreca, A., AmmassariTeule, M., et al. (2016). eEF1B $\gamma$ binds the Che-1 and TP53 gene promoters and their transcripts. J. Exp. Clin. Cancer. Res. 35:146. doi: 10.1186/s13046-0160424- $\mathrm{x}$

Plant, E. P., Nguyen, P., Russ, J. R., Pittman, Y. R., Nguyen, T., Quesinberry, J. T., et al. (2007). Differentiating between near- and non-cognate codons in Saccharomyces cerevisiae. PLoS One 2:e517. doi: 10.1371/journal.pone.000 0517

Puts, G. S., Leonard, M. K., Pamidimukkala, N. V., Snyder, D. E., and Kaetzel, D. M. (2018). Nuclear functions of NME proteins. Lab. Invest. 98, 211-218. doi: 10.1038/labinvest.2017.109

Sasikumar, A. N., Perez, W. B., and Kinzy, T. G. (2012). The many roles of the eukaryotic elongation factor 1 complex. Wiley Interdiscip. Rev. RNA 3, 543-555. doi: 10.1002/wrna.1118

Serpinskaya, A. S., Tuphile, K., Rabinow, L., and Gelfand, V. I. (2014). Protein kinase Darkener of apricot and its substrate EF1 $\gamma$ regulate organelle transport along microtubules. J. Cell Sci. 127, 33-39. doi: 10.1242/jcs. 123885

Sheu, G. T., and Traugh, J. A. (1997). Recombinant subunits of mammalian elongation factor 1 expressed in Escherichia coli. Subunit interactions, elongation activity, and phosphorylation by protein kinase CKII. J. Biol. Chem. 272, 33290-33297. doi: 10.1074/jbc.272.52.33290

Shi, Y., Di Giammartino, D. C., Taylor, D., Sarkeshik, A., Rice, W. J., Yates, J. R. III, et al. (2009). Molecular architecture of the human pre-mRNA 3' processing complex. Mol. Cell 33, 365-376. doi: 10.1016/j.molceCl.2008.12.028

Takano, M., Otani, M., Kaji, T., Sano, K., Hamada-Kanazawa, M., and Matsuyama, S. (2016). Proteomic analysis of mouse choroid plexus cell line ECPC-4 treated with lipid A. Inflamm. Res. 65, 295-302. doi: 10.1007/s00011-016-0916-3

Trosiuk, T. V., Shalak, V. F., Szczepanowski, R. H., Negrutskii, B. S., and El'skaya, A. V. (2016). A non-catalytic N-terminal domain negatively influences the nucleotide exchange activity of translation elongation factor $1 \mathrm{~B} \alpha$. FEBS J. 283, 484-497. doi: 10.1111/febs.13599

Valouev, I. A., Fominov, G. V., Sokolova, E. E., Smirnov, V. N., and Ter-Avanesyan, M. D. (2009). Elongation factor eEF1B modulates functions of the release factors eRF1 and eRF3 and the efficiency of translation termination in yeast. BMC Mol. Biol. 10:60. doi: 10.1186/1471-2199-10-60

Vanwetswinkel, S., Kriek, J., Andersen, G. R., Güntert, P., Dijk, J., Canters, G. W., et al. (2003). Solution structure of the 162 residue C-terminal domain of human elongation factor 1Bgamma. J. Biol. Chem. 278, 43443-43451. doi: 10.1074/jbc. m306031200
Veremieva, M., Kapustian, L., Khoruzhenko, A., Zakharychev, V., Negrutskii, B., and El'skaya, A. (2014). Independent overexpression of the subunits of translation elongation factor complex eEF1H in human lung cancer. BMC Cancer 14:913. doi: 10.1186/1471-2407-14-913

Veremieva, M., Khoruzhenko, A., Zaicev, S., Negrutskii, B., and El'skaya, A. (2011). Unbalanced expression of the translation complex eEF1 subunits in human cardioesophageal carcinoma. Eur. J. Clin. Invest. 41, 269-276. doi: 10.1111/j. 1365-2362.2010.02404.x

Wallace, E. W., Kear-Scott, J. L., Pilipenko, E. V., Schwartz, M. H., Laskowski, P. R., Rojek, A. E., et al. (2015). Reversible, specific, active aggregates of endogenous proteins assemble upon heat stress. Cell 162, 1286-1298. doi: 10.1016/j.cell. 2015.08.041

Wu, H., Shi, Y., Lin, Y., Qian, W., Yu, Y., and Huo, K. (2011). Eukaryotic translation elongation factor 1 delta inhibits the ubiquitin ligase activity of SIAH-1. Mol. Cell. Biochem. 357, 209-215. doi: 10.1007/s11010-011-0891-5

Wu, H., Wang, C., Gong, W., Wang, J., Xuan, J., Perrett, S., et al. (2016). The C-terminal region of human eukaryotic elongation factor $1 \mathrm{~B} \delta$. J. Biomol. NMR 64, 181-187. doi: 10.1007/s10858-016-0012-6

Xing, W., Gao, W., Su, H., Wang, S., Zhang, J., Mao, G., et al. (2018). Salidroside influences the cellular cross-talk of human fetal lung diploid fibroblasts: a proteomic approach. Environ. Toxicol. Pharmacol. 58, 114-121. doi: 10.1016/ j.etap.2018.01.001

Xue, R., Peng, Y., Han, B., Li, X., Chen, Y., and Pei, H. (2019). Metastasis suppressor NME1 promotes non-homologous end joining of DNA double-strand breaks. DNA Repair 77, 27-35. doi: 10.1016/j.dnarep.2019.03.003

Yang, W., Shi, J., Zhou, Y., Liu, T., Li, J., Hong, F., et al. (2019). Co-expression network analysis identified key proteins in association with hepatic metastatic colorectal cancer. Proteomics Clin. Appl. 13:e1900017. doi: 10.1002/prca. 201900017

Yin, P., Knolhoff, A. M., Rosenberg, H. J., Millet, L. J., Gillette, M. U., and Sweedler, J. V. (2012). Peptidomic analyses of mouse astrocytic cell lines and rat primary cultured astrocytes. J. Proteome Res. 11, 3965-3973. doi: 10.1021/pr20 $1066 \mathrm{t}$

Zheng, G., Peng, F., Ding, R., Yu, Y., Ouyang, Y., Chen, Z., et al. (2010). Identification of proteins responsible for the multiple drug resistance in 5-fluorouracil-induced breast cancer cell using proteomics analysis. J. Cancer Res. Clin. Oncol. 136, 1477-1488. doi: 10.1007/s00432-0100805-z

Conflict of Interest: The author declares that the research was conducted in the absence of any commercial or financial relationships that could be construed as a potential conflict of interest.

Copyright (C) 2020 Negrutskii. This is an open-access article distributed under the terms of the Creative Commons Attribution License (CC BY). The use, distribution or reproduction in other forums is permitted, provided the original author(s) and the copyright owner(s) are credited and that the original publication in this journal is cited, in accordance with accepted academic practice. No use, distribution or reproduction is permitted which does not comply with these terms. 